\title{
Language learning in the public eye: an analysis of newspapers and official documents in England
}

Article

Accepted Version

Graham, S. and Santos, D. (2015) Language learning in the public eye: an analysis of newspapers and official documents in England. Innovation in Language Learning and Teaching, 9 (1). pp. 72-85. ISSN 1750-1229 doi:

https://doi.org/10.1080/17501229.2014.995766 Available at https://centaur.reading.ac.uk/37988/

It is advisable to refer to the publisher's version if you intend to cite from the work. See Guidance on citing.

Published version at: http://www.tandfonline.com/toc/rill20/current

To link to this article DOI: http://dx.doi.org/10.1080/17501229.2014.995766

Publisher: Routledge

All outputs in CentAUR are protected by Intellectual Property Rights law, including copyright law. Copyright and IPR is retained by the creators or other copyright holders. Terms and conditions for use of this material are defined in the End User Agreement.

www.reading.ac.uk/centaur 
Central Archive at the University of Reading

Reading's research outputs online 
LANGUAGE LEARNING IN THE PUBLIC EYE: AN ANALYSIS OF NEWSPAPERS

AND OFFICIAL DOCUMENTS IN ENGLAND

Suzanne Graham Denise Santos

Institute of Education, University of Reading

\begin{abstract}
This article considers the issue of low levels of motivation for foreign language learning in England by exploring how language learning is conceptualised by different key voices in that country through the examination of written data: policy documents and reports on the UK's language needs, curriculum documents, and press articles. The extent to which this conceptualisation has changed over time is explored, through the consideration of documents from two time points, before and after a change in government in the UK. The study uses corpus analysis methods in this exploration. The picture that emerges is a complex one regarding how the 'problems' and 'solutions' surrounding language learning in that context are presented in public discourse. This, we conclude, has implications for the likely success of measures adopted to increase language learning uptake in that context.
\end{abstract}

\title{
Keywords
}

Language learning; discourse analysis; attitudes; policy; media discourse

\section{Introduction}

A common theme within research into motivation for language learning in England is the status of English as a global language and its possible negative impact on such motivation, because any instrumental incentives to learn a foreign language are likely to be heavily reduced. This however makes it all the more important to foster other more intrinsic forms of motivation (Graham 2004).

Learners' disaffection in England has also been attributed to the low 'value' or importance they attach to language study (Blenkinsop et al. 2006), and 
to the perceived difficulty they associate with it (Erler and Macaro 2011; Graham

2004). These two factors correspond to what one might call both halves of expectancy-value models of motivation (as outlined, for example, in Wigfield and Eccles 2000): expectations of success, alongside perceived value in achieving such success, with value not restricted to its instrumental sense but including interest and enjoyment.

If these factors are deemed fundamental aspects of motivation, then arguably the messages conveyed in public discourse (e.g. in the media and curriculum documents), about the 'value' of language learning and how likely success in that enterprise is, may have an impact on public attitudes, including those of learners (Coleman 2009; Kramsch 2005). Before such an argument can be made, however, a systematic critical analysis of the public discourse surrounding language learning is required, an area which seems to have been neglected in recent research. In this article we aim to address this gap by looking at the ways foreign languages and their learning are "thematised" (Ensslin and Johnson 2006), i.e. how 'language' is represented or discussed in the media and in key official documents in England.

\section{Context}

Key policy changes have occurred in England regarding language learning in recent years. First, in 2004, under a Labour government, language study beyond age 14 became optional, and the number of pupils taking a GCSE (General Certificate in Secondary Education, the qualification taken at age 16) in a Modern Foreign Language (MFL) decreased dramatically. Second, under the current Conservative/Liberal Democrat Coalition in government since 2010 the 
'EBacc' was introduced in 2011, a performance measure for schools assessing the percentage of pupils gaining a good GCSE in five subjects, including an MFL. This has resulted in a slightly increased take-up at GCSE, but not beyond that (Tinsley and Board 2013).

\section{Related studies}

A common theme in studies considering how language learning is presented in policy and curriculum documents in the early 2000s is the heavily instrumental rationale advanced for language study (Lawes 2007; Mitchell 2003; Pachler 2002). This coincides with "the language of management" noted in educational documents in general in the pre-2010 period (Hayward et al. 2006, 195). Interestingly, in curriculum areas such as history, this language of management has given way post-2010, i.e. with a change of government, to a tone emphasising the importance of academic rigour, of ensuring "that history is taught as a proper subject, so that we can celebrate the distinguished role of these islands in the history of the world, (...) the way in which, since 1688 , this nation has been a beacon for liberty", in comments made in 2010 by Michael Gove, the then Coalition Minister of Education (emphasis added).

Similarly, the Foreword to the 2010 Department for Education White Paper outlines the government's educational stance:

So much of the education debate in this country is backward looking: have standards fallen? (...) what really matters is how we're doing compared with our international competitors. That is 
what will define our economic growth and our country's future.

(...) at the moment we are standing still while others race past (...)

no education system can be better than the quality of its teachers.

(3) (emphasis added)

Thus language related to 'keeping up' is used to focus the reader clearly on the irresistible need to move forward, improve educational standards, and leave the implied failures of the past behind (Lumby and Muijs 2014). Whether such changing language patterns post-2010 can also be detected in policy discourse about, and rationales for, language learning is thus clearly of interest.

As to the press, an important study by Lanvers and Coleman (2013) investigates how language learning is discussed therein by looking at the themes covered in a range of newspapers between 2010 and 2012 and by discussing how these themes relate to the publications' political orientations. They found that the most frequently occurring themes were the decline in specific languages, the importance of language skills for economic and employment reasons, the UK's lack of linguistic competence, and the benefits to the individual of language learning (the latter in broadsheets, left-leaning publications and the local press, but rarely in the tabloids). Overall, they note how the 'crisis' in language learning is predominantly framed in economic terms regarding the 'value' of language learning and with a largely negative tone.

In the present study we aimed to further explore many of the questions addressed by Lanvers and Coleman (2013) using corpus methods to identify themes and patterns of language usage in public discourses, including their tones (negative or positive). In addition, while previous studies have taken a cross- 
sectional perspective, we were interested in whether those themes and language patterns have changed to match the change in political orientation in 2010 of the ruling government in England (from centre-left to centre-right). As such, the following research questions were formulated:

(1) How is language learning thematised in key public written texts?

(2) How do such texts portray (i) the value of learning a language and (ii) success in language learning?

(3) Does this thematisation differ pre- and post-2010?

\section{Data selection}

Our corpus came from newspaper articles and official documents ${ }^{1}$ relating to instructed language learning, and from two time-points: 2007 and 2013, i.e. before and after the change from a Labour to a Conservative/Liberal Coalition government. We are aware that the two types of documents we consider, the press and official documents, have different aims and audiences, but discussing these differences is beyond the scope of the present article.

\section{Press articles}

Like Lanvers and Coleman (2013), we selected newspapers representing a balance in political orientation and style:

[TABLE 1] 
We then searched for the word 'language' in those papers over four weeks at each time-point: two weeks before and after the results for both GCSE and A level (the examination taken at age 18) were released. We sought insights into media coverage at a time of year when attention towards educational issues is heightened, and when presumably language learning is being discussed within the context of questions regarding its value and expectations of success. We disregarded articles containing 'language' whose focus was not on foreign/second language teaching and learning. Like Lanvers and Coleman (2013) we also disregarded 'Letters to the Editor'. In 2007 we accessed articles at the point when they were published online, as part of a larger study; for 2013, articles were selected retrospectively, using the database UK Newsstand. Figures 1 and 2 give details about our press corpus. Note that A-level and GCSE results were released on Days 7 and 14 respectively in our search.

[FIGURES 1] [FIGURE 2]

\section{Official documents}

For both time-points, we selected firstly the National Curriculum for MFL (QCA 2007 and DfE 2013, henceforth 'NC 2007' and 'NC 2014', respectively), a document whose aim is to set out what should be taught between the ages of 11 and 14 in England (Key Stage 3, KS3). Additionally, we chose reviews of language learning: for pre-2010, the Dearing Review Final Report (Dearing and King 2007; 'Dearing' from now on), a government-sponsored investigation into issues of motivation and uptake in MFL and whose recommendations influenced post- 
2007 curriculum developments. Post-2010, we selected a report commissioned by a funding body, the British Academy (Tinsley 2012), 'Languages: the State of the Nation. Demand and supply of language skills in the UK' ('State', from now on).

We analysed the main body of the text in each review (i.e. excluding headers and footnotes, references, appendices). For the National Curriculum documents, we analysed the introductory 'Importance' statement, the Programme of Study (PoS), and any explanatory notes. We disregarded the 2007 descriptors for what learners are meant to attain (Attainment Target Levels), as they do not exist for 2014, although we acknowledge, like Mitchell (2003), that such descriptors do in themselves convey messages about what is 'important' in language learning.

\section{Data analysis}

We used corpus methods in our analysis using AntConc 3.4 computer software. For all data sets we began with frequency counts for content words of salience for our analysis following themes emerging from the literature review (e.g., 'problem', 'work', 'policy') or more commonsensical issues we wanted to explore (e.g. 'pupils', 'teachers', 'foreign language', 'French', 'Spanish', 'German'). Table 2 presents a frequency list of those content words.

[TABLE 2].

We also looked for frequent collocates (i.e., words that appear together) and clusters (i.e., groups of words in sequence) associated with the word 
'language(s)', and for some conducted further analyses through the generation of concordance lines (i.e., words/phrases and their surrounding context). An example is given below showing two concordance lines for 'foreign languages' in the press data in 2007. The searched phrase is given in bold in the centre of the line and it is surrounded by its co-text, revealing patterns of association around the searched words, i.e. that 'foreign languages' co-occur with words such as 'maths', 'GCSE', 'grades', being presented as a 'school subject'.

1 of GCSE English, maths, science and a foreign language. Only 25.8 per cent last year got Cs 2 achieving grade $\mathrm{C}$ or above in a modern foreign language as well as science". Only half of

Thus an examination of patterns of discourse can give insights into what messages are being conveyed implicitly, which may "even be at odds with an overt statement" (Hunston, 2002,109).

Within the press data we also identified the themes associated with language learning, drawing on the categories used by Lanvers and Coleman (2013) plus others emerging from our data. The two authors of the present article carried out this coding independently, reaching an inter-rater reliability level of 76\%. Final agreement was achieved through discussion.

\section{Findings}

Here we discuss the themes identified within each document source with a focus on what they suggest about (i) the 'value' of language learning and (ii) the position towards 'success', i.e. how 'being successful' at language is 
characterized. Following Lanvers and Coleman (2013) we also discuss whether there is a predominant tone (negative or positive) regarding whether such success is achievable.

\section{Press articles}

Within the 2007 press data, 'language' is predominantly thematised as a school subject, an end-product of schooling. This is perhaps unsurprising, given the timing of our data collection, but such references as "having a second language" (The Daily Mirror, 23 August 2007) present language as an object of possession, with little focus on the processes and gains involved in this 'possession'. Hence 'value' appears as academic value. Furthermore, the term 'value' is almost never used at either time-point in relation to language learning, except once in a quote by the chief executive of an examination board: "The signals young people are getting are not particularly strong about the future value of having a language qualification (...)" (Daily Mail, 23 August 2007). Also notable by their relative absence are references to 'language' in association with participation in the workplace: in 2007 'language' collocates with 'job', 'work' (-place) or 'employ' (-ment, -er, -ee) in the four papers, albeit infrequently (x 2 in The Telegraph; x3 in The Daily Mirror; x11 in The Guardian; x6 in The Daily Mail). In 2013 however there is only one example of such collocates (in The Telegraph).

The strong conceptualization of language as school subject is also conveyed through the nouns that frequently collocate with 'language' which are: other school subjects especially core ones like 'science' (x7), 'English' (x6) and 'maths' (x5); also 'GCSE' (x5), 'lessons' ( $\mathrm{x} 4$ ) and 'teaching (x4). The twenty 
concordance lines containing 'foreign language' confirm this trend: eight of them present the phrase next to other school subjects, and co-occurring words include 'lessons' (x2), 'study/ing' (x2) and 'curriculum' (x1). Within such a conceptualization of language, success is defined in terms of examination grades.

This association of languages with other subjects and GCSE frequently comes across in the context of 'hierarchies', with certain subjects (including languages) being 'harder', more harshly graded, and more 'prestigious' because more difficult. Such associations also occur in the 2013 press data when the EBacc is mentioned, but in general language is less clearly thematised as a school subject there. In 2013, words that most frequently collocate with 'language' are 'English' (x19), 'Welsh' (x5) and 'learning' (x5). Interestingly, the latter are found in broadsheets and often appear together with words signaling a negative idea (such as 'concerns', 'lamentable' and 'decline'), revealing a negative semantic prosody. Out of the 26 concordance lines generated with uses of 'foreign language' 12 thematise language as a school subject with a focus on the decline in update and/or exam results.

Overall, uptake and assessment issues occur frequently in the press. Shades of negativity or positivity vary to a degree across time (Table 3). In 2013, the most frequent themes are either neutral (e.g. the EBacc) or positive (e.g. general increase in uptake), themes which were also identified as common by Lanvers and Coleman (2013). The EBacc is associated with assessment twice in 2013 (both times in The Telegraph), giving assessment a more positive tone than it had in 2007. Then, assessment is the most frequent theme, appearing five times in the two broadsheets but not in the tabloids, and is presented as a problem, as illustrated by the following: “... a French examiner reveals how tests 
have been reduced to little more than a memory exercise as pupils get by with little understanding of a foreign language." (The Telegraph, 23 August 2007)

\section{[TABLE 3]}

Again relating to success or otherwise, a gender gap in attainment, another negative issue in language learning, is the second most frequent theme in the 2007 data, appearing once in each of the four newspapers. Yet by 2013, this theme becomes infrequent or non-existent. Instead 'language' is predominantly associated with English language as a school subject or with English as a second language (12 occurrences), a theme beyond the scope of interest of our study (although it may reflect other concerns in the press such as immigration or L1 literacy issues).

The theme 'general increase in uptake in languages' appears to be closely related to the EBacc in the press coverage, co-occurring nine times (five in The Telegraph, twice in The Mirror and also twice in The Guardian). While this might suggest greater positivity in the portrayal of languages, collocations suggest that across time, the press, across broadsheets and tabloids, wishes to portray a scenario that is still a cause for concern. Indeed, the word 'concern(-s; ed)' collocates eight times with 'language' in 2013 (against 3 times in 2007) and 'worrying' appears in such collocations eight times (against nil in 2007), in both the words of journalists and in quotes from politicians, as in one from the then Labour Shadow Education Secretary Stephen Twigg, "It's good to see some of those pupils go on to do a language GCSE. However, it is worrying that this trend is not continuing to A Level as yet.' (The Telegraph, 22 August 2013) Similarly, in 
2013, 'languages' collocate with 'fall(-en; -s)', 'drop (-ing; -pped)' and 'decline', appearing respectively 11 times, six times and six times (as opposed to 5, 7 and 4 in 2007). Such emphasis on negative issues by the press echoes Bollen and Baten's (2010) claim, citing Thomas (2003), that the media often adopt a 'discourse of crisis' (412) in relation to educational issues, thus suggesting in this context that 'success' is hard to achieve. Furthermore, in contrast with Lanvers and Coleman (2013) we found little reference to the personal and professional benefits of language learning in 2013, although these themes occurred relatively more frequently in 2007. Overall success is conceptualised in the press data around exams: out of the 16 occurrences of 'success*', 14 relate to success in exam results $(n=11)$ or the introduction of the EBacc $(n=3)$.

\section{Official documents}

The National Curriculum, 2007 and 2014

Because few of the searched words occur more than once or twice in either document (as seen in Table 2) our analysis focused on the words that do occur more frequently. In both documents, 'pupil' occurs more frequently than either 'student' or 'learner', a choice that underlines the school-based nature of the curriculum and, as in the press, might evoke the view of languages as objects of academic performance. Hence we looked at collocations with 'pupil' to see what is expected of them. In 2007, verbs convey, overall, a sense of pupil discovery, active learning and skill development positioning language not simply as a school subject but rather as a resource enabling pupils to "appreciate 
different countries" (165) alongside "using language that they have encountered" (167). The sole use of 'success*' in NC 2007 (there is none in NC 2014) is arguably linked with this use of language as action, with the curriculum aims being "for all young people to become: successful learners who enjoy learning, make progress" (165).

In NC 2014, verbs associated with pupils are similarly active, but less emphasis is placed on exploration and more on direct actions and cognitive pursuits, whereby language study at KS3 should "provide suitable preparation for further study. Pupils should be taught to...." (2). This last example highlights, furthermore, an important difference between the two curricula: in 2007, the key thrust of the PoS is on what learners would achieve ("Pupils should be able to"); in 2014, the PoS begins with "Pupils should be taught to". This suggests transmission of knowledge by the teacher, rather than knowledge and skills developed by the learner, possibly pointing to focus on teaching rather than learning, as does the higher frequency of both 'teacher' and 'teaching' in 2014.

'Education' has a surprisingly low level of occurrence in both documents. Its single occurrence in 2007 points to skill and employment prospects associated with foreign language learning, "a lifelong skill for education, employment and leisure in this country" (165). In 2014 the emphasis is less on work than on the development of insights: "A high-quality languages education should foster pupils' curiosity and deepen their understanding of the world" (1). Such focus on the global scenario also emerges in the few occurrences of 'work' in the two curricula: in NC 2007, employment is associated with "the world in which we live and work" (165); in the sole use of 'work' in NC 2014, languages enable "pupils to study and work in other countries" (1). These examples suggest 
there is value associated with language learning for the workplace, for personal development and for global participation. However, because those uses are so infrequent, such value is arguably downplayed in those documents. Indeed, 'value' does not occur in NC 2014 and its sole occurrence in NC 2007 involves learning about other cultures and their "religious beliefs, social customs, traditions, values" (166).

Table 4, listing searched words beyond those in Table 2 , suggests other changes in emphasis over time, reflecting perhaps shifts in how the value or purpose of language learning is conceptualised in the NC: a decrease in emphasis on 'culture' in 2014, on dealing with the 'unfamiliar' (but perhaps reappearing as 'spontaneity'), on 'skills', and a stronger emphasis on 'accuracy', 'increasing', 'vocabulary', 'and 'foundations'. 'Develop' also seems to have grown in relative importance in 2014. It is important to acknowledge, however, that in 2007, many of these words appeared in the Attainment Targets, which are not analysed here.

[TABLE 4]

Interestingly, in 2014, 'accurate' and 'accurately' are most often associated with grammar and translation $(\mathrm{x} 4)$, as in 'take part in discussion about wider issues, use accurate grammar, spelling and punctuation '(2). In 2007 the one instance of 'accuracy' in the PoS may reflect more a process than a product: "redraft their writing to improve accuracy and quality" (167). This difference also seems to show in what pupils are supposed to 'develop' according to the two documents. In 2007, the development of skills and strategies seems at the forefront, where pupils are given, for example "opportunities to develop their 
listening, speaking” (165). In 2014 by contrast, while 'develop' is linked to a degree with acquiring certain kinds of competences and knowledge (although not really skills), such as "[develop] an appreciation of a range of writing", or to "develop and use a wide-ranging vocabulary" (2), it also seems to be associated more strongly with the notion of complexity, with learners taught to "express and develop ideas clearly" (2), for example. This may also relate to the higher frequency of 'increase*' in 2014, associated with increases in spontaneity, independence, range of grammar and accuracy.

Perhaps most striking are the fewer references to intercultural understanding in NC 2014 compared with 2007. In 2014 it occurs principally in the statement about the importance of language learning, and hence concerns its value and purpose: “Learning a foreign language is a liberation from insularity and provides an opening to other cultures" (1), positioning language learning, perhaps, as something that a cultured and educated person does.

The justification for language learning in NC 2007 has a different ring to it, focusing more on 'citizenship' and personal development through selfexamination and an awareness of the relativity of values:

Learning languages contributes to mutual understanding, a sense of global citizenship and personal fulfilment. Pupils learn to appreciate different countries, cultures, communities and people. By making comparisons, they gain insight into their own culture and society. (165) (emphasis added) 
In order to examine how the value of language learning, and the likelihood of success, are presented in these documents we looked at some collocation patterns with 'language'. In Dearing, 'support' as a verb or noun is used frequently (x13), mainly in left position (as in "companies to support languages" (6)). Six of the 10 examples of 'learn' or 'learnt' in that report relate to the need to promote the learning of languages (e.g. "so that more young people keep up language learning" (1)). These patterns suggest a deficit view of language learning, as something in urgent need of reviving, and in which success is hard to come by, although there may be some positivity about it - "a foreign language is culturally and economically indispensable” (30, see also below).

The deficit view is coupled with the fact that in that report 'learners' more often appear as the object of a verb rather than as the subject, suggesting that, rather than being active participants in acquiring a language, they are on the receiving end of policy initiatives, e.g. " it will be possible to motivate all or most learners" (11). Similarly, 'success' is infrequently used in connection with learners' successes and more often occurs with teaching, policies or departments. This last point is equally true of State, where again students appear as relatively passive, needing encouragement in undertaking a difficult task. Difficulty and perhaps lack of success are also implied in the nouns and adjectives linked with learners, which refer mostly to learner variables, often their socio-economic status or levels of attainment.

The language of economics is a key feature of both reports. 'Value' in Dearing is largely used in relation to work and the economy, where employers should "consider what more they can do to promote the value of language skills for business" (1). Uses of 'skill' in that report convey this economic focus in 10 of 
the 24 occurrences of the word. In State the majority of the many references to 'skills' are in the context of employment and economic factors, even more strongly than in Dearing, and there is implied criticism of previous initiatives, which "have tended to address the learner dimension in isolation from the demand side" (20). Here again, there is a sense of negativity, framed within the language of the market, as in "a growing deficit in foreign language skills at a time when globally, the demand for language skills is expanding" (9).

While there are instances (seven out of 28) of 'value' being used in State in connection with society and communities, the overriding sense from an analysis of how the term is used is that the purpose of language learning is its contribution for society's economy rather than its potential contribution to individuals' wider development.

\section{Discussion and conclusion}

Here we summarise answers to our research questions: similarities and differences in the way in which language is thematised in different data sets, the portrayal of success and value, and changes/similarities across time. In the press, in 2007, language is depicted predominantly as a reified school subject with success linked to exam results. While the thematisation of languages as a school subject has abated by 2013 , there is even less sense of there being any value to languages beyond this, and the relative absence of the term 'value' at both time points is remarkable, as are the infrequent links made between language learning and personal development or the workplace. Across time there is a persistent tone of negativity, both in terms of likely success, and of languages remaining in 'crisis', even when an increase in uptake for languages is noted in 
the 2013 press. These findings may be unsurprising, given the well-known focus held by the press on 'bad news'.

The two National Curriculum documents present quite different views of language learning. NC 2007 suggests more clearly than perhaps any document in our data set that languages extend beyond the classroom and bring enjoyment, personal and social development. Moreover, through skill development, there is a sense that success is possible, also linked with enjoyment. By 2014, mirroring the tone of the 2010 Education White Paper, the theme of languages as school subject seen in the 2007 press is back much more strongly, with a focus on higher standards, but not on skills, and on teaching rather than learning. There is some sense that languages are what an educated person studies (c.f. the vision of history as a subject referred to earlier), and success seems to be equated with a high level of performance in terms of accuracy and complexity.

The negative tone seen in the press also occurs in the reports, even though their stated intention is to offer a boost for languages. Unlike the press, where there is little association between languages and employment, both reports imply a utilitarian view of the value of language learning, which seems to be prized less for what it can do for learners as individuals and more for what it can contribute to the economy, even though State's expressed intention is to consider the UK's need for languages more broadly.

If we assume that how languages are presented in public discourse has some influence on learners' attitudes towards them, and we try to relate that presentation to theories of motivation, then it is not difficult to see why language uptake is poor in England. At the outset we referred to two key components of motivation, namely learners' perceptions of the 'value' of language learning, and 
their expectations of success. Research indicates that both are vital for motivation, and indeed that learners' perceptions of the value of a subject (and importantly beyond instrumental value) tend to increase with their expectations of success (Mills, Pajares, and Herron 2007). The dominant discourse of negativity in our data (especially in the press and the reports) arguably conveys a strong message that success in languages is unattainable. Additionally, there is no coherent narrative in public discourse of what the 'value' of languages is, beyond a subject in the curriculum, or as a means of boosting the economy, except perhaps in NC 2007, where it seems to have a broader worth. While acknowledging that the link between curriculum rationales, educational policy and learner responses is a complex one (cf. Mitchell, 2003), we would argue that it is therefore perhaps not surprising if learners themselves do not understand clearly what the value of language learning is, or do not see success in that enterprise as a goal that is achievable or worth pursuing.

\section{References}

Blenkinsop, S., T. McCrone, P. Wade, and M. Morris. 2006. How do Young People Make Choices at Age 14 and Age 16?: Research Report 773. London: DfES. http://www.nfer.ac.uk/publications/YPM02/YPM02_home.cfm

Bollen, K. and K. Baten. 2010. "Bilingual Education in Flanders: Policy and Press Debate (1999-2006)." The Modern Language Journal 94 (3): 412-433. doi:

10.1111/j.1540-4781.2010.01089.x 
Coleman, J.A. 2009. "Why the British do not Learn Languages: Myths and Motivation in the United Kingdom." Language Learning Journal, 37(1): 111-127. doi: $10.1080 / 09571730902749003$

Dearing, R. and L. King. 2007. The Languages Review. London: DfE.

Department for Education. 2010. The Importance of Teaching: Schools White Paper. http://www.education.gov.uk/b0068570/the-importance-of-teaching/

Department for Education. 2013. Languages Programmes of Study: Key Stage 3. National Curriculum in England.

https://www.gov.uk/government/publications/national-curriculum-in-englandlanguages-progammes-of-study

Ensslin, A. and S. Johnson. 2006. "Language in the News: Investigations into Representations of 'Englishness' Using Wordsmith Tools." Corpora: Corpus-based Language Learning, Language Processing and Linguistics 1: 153-185.

Erler, L. and E. Macaro. 2011. “Decoding Ability in French as a Foreign Language and Language Learning Motivation." The Modern Language Journal 95(4): 496518. doi: 10.1111/j.1540-4781.2011.01238.x

Gove, M. 2010. Speech to the Conservative Party Conference in Birmingham. www.epolitix.com/latestnews/article-detail/newsarticle/speech-in-fullmichael-gove/ 
Graham, S. 2004. “Giving up on Modern Foreign Languages? Students' Perceptions of Learning French". The Modern Language Journal 88 (2):171-191. doi: 10.1111/j.0026-7902.2004.00224.

Hayward, G., A. Hodgson, J. Johnson, A. Oancea, R. Pring, K. Spours, S. Wilde, and Wright. 2006. The Nuffield Review of 14-19 Education and Training: Annual Report 2005-06. Oxford: University of Oxford Department of Educational Studies.

Hunston, S. 2002. Corpora in Applied Linguistics. Cambridge: Cambridge University Press.

Kramsch, C. 2005. “Post 9/11: Foreign Languages between Knowledge and Power." Applied Linguistics 26: 545-567. doi: 10.1093/applin/ami026

Lanvers, U. and J.A. Coleman. 2013. “The UK Language Learning Crisis in the Public Media: A Critical Analysis". Language Learning Journal. <Vol, page numbers> doi: 10.1080/09571736.2013.830639

Lawes, S. 2007. “Foreign Languages Without Tears”. In The Corruption of the Curriculum, edited by R. Whelan, 86-97. London: Civitas. 
Lumby, J. and D. Muijs. 2014. “Corrupt Language, Corrupt Thought: The White Paper The Importance of Teaching". British Educational Research Journal, 40:523538. doi: 10.1002/berj.3093

Mills, N., F. Pajares, and C. Herron. 2007. "Self-efficacy of College Intermediate French Students: Relation to Achievement and Motivation." Language Learning 57: 417-442. doi: 10.1111/j.1467-9922.2007.00421.x

Mitchell, R. 2003. “Rationales for Foreign Language Education in the 21st Century". In, Applied Linguistics and Communities of Practice, edited by S. Sarangi and T. V. Leeuwen, 114-131. London: Continuum

Pachler, N. 2002. "Foreign Language Learning in England in the 21 ${ }^{\text {st }}$ Century." Language Learning Journal 25: 4-7.

Qualifications and Curriculum Authority. (2007). National Curriculum. Programme of Study for Key Stage 3 and Attainment Targets. http://www.education.gov.uk/schools/teachingandlearning/curriculum/second ary/b0 0199616/mfl

Tinsley, T. 2012. Languages: The State of the Nation. Demand and Supply of Language Skills in the UK. London: The British Academy.

Tinsley, T. and K. Board. 2013. Findings from the 2012 Language Trends Survey. http://old.n-somerset.gov.uk/NR/rdonlyres/F30CAAFC-B0C5-440B-BB7FECDD2C2D4EC3/0/Findingsfromthe2012languagetrendssurveypdf.pdf 
Wigfield, A. and J. Eccles. 2000. “Expectancy-value Theory of Achievement Motivation." Contemporary Educational Psychology 25: 68-81.

doi: 10.1006/ceps.1999.1015 
Table 1: Press quality and political orientation

\begin{tabular}{|l|l|l|}
\hline & Right-leaning & Left-leaning \\
\hline Tabloid & The Daily Mail & The Daily Mirror \\
\hline Broadsheet & The Daily Telegraph & The Guardian \\
\hline
\end{tabular}


Table 2: Frequency of searched words in the data

\begin{tabular}{|c|c|c|c|c|c|c|c|c|c|c|c|c|}
\hline Document & $\begin{array}{l}\mathrm{DM}^{2} \\
2007\end{array}$ & $\begin{array}{l}\text { DM } \\
2013\end{array}$ & TM 2007 & TM 2013 & $\begin{array}{l}\text { TG } \\
2007\end{array}$ & $\begin{array}{c}\text { TG } \\
2013 \\
\end{array}$ & $\begin{array}{c}\text { TT } \\
2007\end{array}$ & $\begin{array}{c}\text { TT } \\
2013 \\
\end{array}$ & $\begin{array}{c}\text { NC } \\
2007\end{array}$ & $\begin{array}{l}\text { NC } \\
2013\end{array}$ & Dearing & State \\
\hline $\begin{array}{l}\text { Total no. } \\
\text { words }^{1}\end{array}$ & 1,037 & 176 & 1287 & 2315 & 6,234 & 13962 & 7,792 & 15594 & 1,525 & 271 & 12,747 & 48,758 \\
\hline language* & 1 & 4 & 18 & 14 & 30 & 49 & 37 & 75 & 66 & 22 & 318 & 1755 \\
\hline $\begin{array}{l}\text { foreign } \\
\text { language* }\end{array}$ & 1 & 0 & 3 & 5 & 7 & 4 & 9 & 17 & 2 & 4 & 2 & 154 \\
\hline $\begin{array}{l}\text { second } \\
\text { language* }\end{array}$ & 0 & 0 & 2 & 0 & 0 & 1 & 1 & 1 & 0 & 0 & 2 & 8 \\
\hline French & 1 & 0 & 4 & 8 & 6 & 11 & 13 & 26 & 1 & 0 & 6 & 118 \\
\hline German & 2 & 0 & 5 & 8 & 5 & 9 & 6 & 18 & 1 & 0 & 4 & 101 \\
\hline Spanish & 2 & 0 & 1 & 8 & 3 & 7 & 4 & 13 & 1 & 0 & 4 & 101 \\
\hline Mandarin & 0 & 0 & 2 & 0 & 1 & 0 & 1 & 3 & 1 & 0 & 1 & 17 \\
\hline Chinese & 0 & 0 & 2 & 2 & 1 & 1 & 0 & 0 & 0 & 0 & 0 & 32 \\
\hline Arabic & 0 & 0 & 0 & 2 & 0 & 2 & 0 & 2 & 0 & 0 & 0 & 33 \\
\hline GCSE* & 0 & 3 & 1 & 10 & 17 & 37 & 52 & 112 & 0 & 0 & 43 & 91 \\
\hline A-Level* & 17 & 0 & 5 & 3 & 29 & 24 & 19 & 33 & 0 & 0 & 12,747 & 56 \\
\hline test* & 1 & 0 & 1 & 0 & 2 & 4 & 22 & 22 & 0 & 0 & 0 & 16 \\
\hline exam* & 8 & 0 & 4 & 8 & 19 & 123 & 71 & 139 & 0 & 0 & 6 & 32 \\
\hline student* & 11 & 0 & 4 & 20 & 31 & 93 & 19 & 73 & 0 & 0 & 7 & 129 \\
\hline pupil* & 6 & 1 & 2 & 20 & 17 & 53 & 52 & 118 & 18 & 9 & 9 & 88 \\
\hline teacher* & 0 & 0 & 5 & 1 & 9 & 24 & 31 & 16 & 1 & 0 & 56 & 62 \\
\hline teach* & 1 & 0 & 7 & 1 & 5 & 31 & 50 & 24 & 2 & 5 & 72 & 55 \\
\hline parents & 0 & 0 & 0 & 0 & 2 & 15 & 4 & 4 & 0 & 0 & 30 & 5 \\
\hline department* & 0 & 0 & 0 & 0 & 3 & 9 & 3 & 4 & 0 & 0 & 5 & 15 \\
\hline study* & 0 & 0 & 1 & 6 & 18 & 31 & 9 & 21 & 5 & 5 & 25 & 101 \\
\hline learn* & 1 & 0 & 6 & 0 & 9 & 16 & 7 & 17 & 15 & 5 & 78 & 130 \\
\hline learner/s & 0 & 0 & 0 & 0 & 0 & 1 & 1 & 0 & 1 & 0 & 21 & 38 \\
\hline $\operatorname{know}(\mathrm{s})(\mathrm{n})$ & 0 & 0 & 1 & 0 & 1 & 12 & 1 & 7 & 3 & 1 & 4 & 8 \\
\hline $\operatorname{know}(s)(n)$ & 0 & 0 & 1 & 0 & 1 & 12 & 1 & 7 & 3 & 1 & 2 & 13 \\
\hline knowledge & 0 & 0 & 0 & 0 & 0 & 1 & 2 & 3 & 9 & 0 & 24 & 542 \\
\hline skill* & 0 & 0 & 0 & 1 & 1 & 3 & 13 & 5 & 12 & 1 & 0 & 3 \\
\hline educate* & 0 & 0 & 0 & 0 & 1 & 0 & 1 & 1 & 0 & 0 & 16 & 188 \\
\hline
\end{tabular}




\begin{tabular}{|c|c|c|c|c|c|c|c|c|c|c|c|c|}
\hline education & 1 & 0 & 2 & 10 & 20 & 39 & 26 & 51 & 1 & 1 & 2 & 5 \\
\hline cause* & 0 & 0 & 0 & 0 & 0 & 6 & 0 & 4 & 0 & 0 & 4 & 13 \\
\hline problem* & 1 & 0 & 0 & 0 & 5 & 3 & 4 & 13 & 0 & 0 & 14 & 43 \\
\hline issue* & 0 & 0 & 0 & 0 & 1 & 4 & 2 & 1 & 0 & 0 & 78 & 130 \\
\hline policy/policies & 0 & 0 & 1 & 2 & 0 & 1 & 1 & 3 & 0 & 0 & 7 & 92 \\
\hline textbook* & 0 & 0 & 1 & 0 & 0 & 0 & 0 & 0 & 0 & 0 & 0 & 0 \\
\hline cover* & 0 & 0 & 0 & 0 & 0 & 1 & 1 & 2 & 1 & 0 & 7 & 21 \\
\hline work* & 0 & 0 & 3 & 0 & 6 & 5 & 8 & 4 & 1 & 1 & 6 & 62 \\
\hline abilit* & 0 & 0 & 0 & 0 & 3 & 1 & 6 & 4 & 2 & 0 & 7 & 14 \\
\hline talent* & 0 & 0 & 0 & 1 & 1 & 0 & 0 & 0 & 0 & 0 & 1 & 1 \\
\hline success* & 1 & 0 & 0 & 1 & 1 & 4 & 2 & 7 & 0 & 0 & 25 & 13 \\
\hline value* & 0 & 0 & 0 & 0 & 2 & 0 & 1 & 6 & 0 & 0 & 14 & 28 \\
\hline standard* & 3 & 0 & 0 & 0 & 1 & 10 & 12 & 12 & 1 & 0 & 3 & 14 \\
\hline
\end{tabular}

Note 1: The table shows that the total number of words varies considerably across the different texts. We have not adjusted the figures in relative terms for the sake of accuracy of representation, but the total number of words in each document allows the reader to see the relative value of key word occurrences.

Note 2: $\mathrm{DM}=$ The Daily Mail; $\mathrm{TM}=$ The Mirror; $\mathrm{TG}=$ The Guardian; $\mathrm{TT}=$ The Telegraph

Note 3: An asterisk indicates searches for any string of words containing the indicated string, for example pupil* will include pupils. 
Table 3: Themes in the press data

\begin{tabular}{|l|l|l|}
\hline Themes & \multicolumn{2}{|c|}{$\begin{array}{c}\text { Number of occurrences (with } \\
\text { percentages in parenthesis) }\end{array}$} \\
\hline & \multicolumn{1}{|c|}{2007} \\
\hline Assessment problems & $5(17 \%)$ & $2(3 \%)$ \\
\hline Gender gap & $4(14 \%)$ & - \\
\hline $\begin{array}{l}\text { Personal and professional benefits of language } \\
\text { learning* }\end{array}$ & $3(10 \%)$ & $2(3 \%)$ \\
\hline 2004 Labour policy* & $3(10 \%)$ & $4(7 \%)$ \\
\hline Easy vs. difficult subjects & $3(10 \%)$ & $3(5 \%)$ \\
\hline Importance of language skills for economy* & $2(7 \%)$ & $1(2 \%)$ \\
\hline Decline of specific languages* & $2(7 \%)$ & $10(16 \%)$ \\
\hline Poor performance and/or poor results & $2(7 \%)$ & - \\
\hline EBacc* & $1(3 \%)$ & $10(16 \%)$ \\
\hline Types of schools and their different profiles & $1(3 \%)$ & - \\
\hline General increase in uptake & $1(3 \%)$ & $11(18 \%)$ \\
\hline Critique of current government* & $1(3 \%)$ & - \\
\hline Changing importance of specific MFL* & $1(3 \%)$ & $4(7 \%)$ \\
\hline Example for 'school subject' & $1(3 \%)$ & $2(3 \%)$ \\
\hline English language as a subject, or ESOL & - & $12(20 \%)$ \\
\hline
\end{tabular}

* denotes categories drawn up from the Lanvers and Coleman (2013) study. Categories from that study which are not found in our data are: anglo centric culture; primary languages; comparison to other countries; negative effect of English as a lingua franca; class

differences; teaching problems and policy announcement. 
Table 4: Additional words with over 2 occurrences in NC 2007 and 2014

\begin{tabular}{|c|c|c|}
\hline Word & NC 2007 & NC 2014 \\
\hline & Count & Count \\
\hline accuracy & 1 & 8 \\
\hline accurate/ly & 0 & 4 \\
\hline citizen & 2 & 0 \\
\hline communicate & 7 & 3 \\
\hline creative & 6 & 2 \\
\hline Culture/intercultural & 11 & 2 \\
\hline develop & 11 & 7 \\
\hline express & 6 & 3 \\
\hline foundation & 1 & 3 \\
\hline grammar & 5 & 6 \\
\hline increase & 2 & 6 \\
\hline knowledge & 9 & 0 \\
\hline learn & 15 & 5 \\
\hline literacy & 2 & 0 \\
\hline literature & 0 & 2 \\
\hline new & 9 & 2 \\
\hline other & 10 & 3 \\
\hline pupils & 20 & 9 \\
\hline skills & 12 & 1 \\
\hline society & 5 & 1 \\
\hline spontaneity & 0 & 2 \\
\hline strategy & 2 & 0 \\
\hline Target [language] & 17 & 0 \\
\hline teach & 3 & 5 \\
\hline translate & 0 & 2 \\
\hline understand & 13 & 7 \\
\hline $\begin{array}{l}\text { Unexpected, unfamiliar, } \\
\text { unpredictable }\end{array}$ & 8 & 2 \\
\hline
\end{tabular}




\begin{tabular}{|l|l|l|}
\hline use & 17 & 7 \\
\hline vocabulary & 1 & 4 \\
\hline wide & 0 & 3 \\
\hline
\end{tabular}

Figure 1

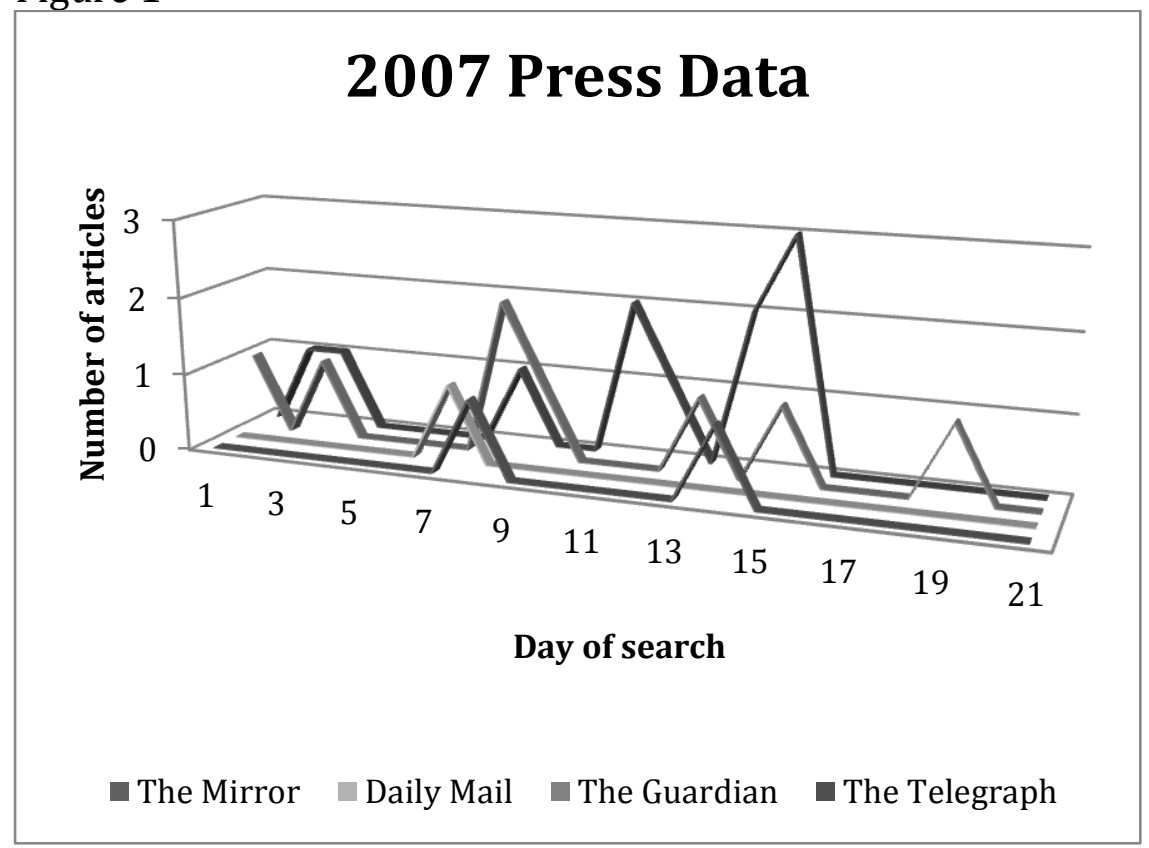

Figure 2 


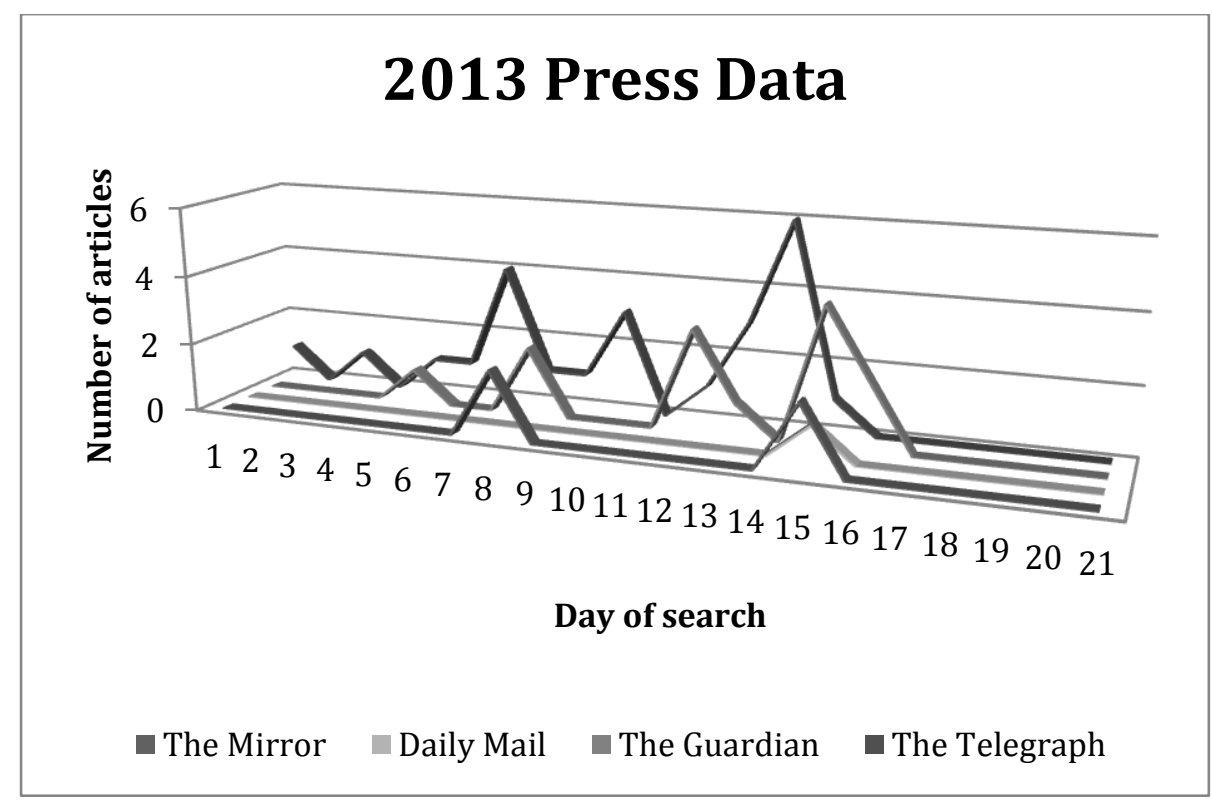

